\title{
Inmunoglobulina E total como marcador de alergia en el noroeste de México
}

Francisca Ramírez-Enríquez ${ }^{1}$, Jesús Prado-Rendón ${ }^{1}$, Jesús Lachica-Valle ${ }^{1}$, Jaime Valle-Leal ${ }^{2}$

\section{Resumen}

ANTECEDENTES: la relación entre IgE total en suero y alergia se ha estudiado para determinar si puede ser un complemento útil para el diagnóstico de alergia.

OBJETIVO: conocer si la IgE sérica total es una herramienta útil en el diagnóstico de alergia en la población pediátrica que acude a la consulta externa de Alergología pediátrica del Hospital General Regional 1, Ciudad Obregón, Sonora.

MATERIAL Y MÉTODO: estudio epidemiológico, observacional, retrospectivo, transversal y analítico de prueba diagnóstica, en el que se revisaron los expedientes de niños entre 3 y 16 años de edad, atendidos en el servicio de Alergología pediátrica. Para el análisis estadístico se utilizó el programa SPSS versión 22 y por medio de una tabla tetracórica se determinó la sensibilidad y especificidad de IgE para el diagnóstico de alergias; se tomaron pruebas cutáneas como patrón de referencia para el diagnóstico de alergias. Se determinó el valor de p entre las variables de estudio con la prueba t de Student.

RESULTADOS: se estudiaron 248 expedientes, el género masculino fue más frecuente (59\%). La sensibilidad de IgE fue de $85 \%$ y la especificidad de 20\%; el punto de corte encontrado fue de $148 \mathrm{UI} / \mathrm{mL}$, concentraciones elevadas de IgE en pruebas cutáneas para aeroalergenos y existencia de síntomas respiratorios.

CONCLUSIONES: la determinación de IgE es una prueba útil de tamizaje inicial en pacientes con sospecha de alergia.

PALABRAS CLAVE: IgE sérica total, atopia, pruebas cutáneas.

Rev Alerg Méx 2016 Jan-Mar;63(1):20-25.

\section{Total immunoglobulin E as marker of allergy at Northeast of Mexico.}

Francisca Ramírez-Enríquez ${ }^{1}$, Jesús Prado-Rendón ${ }^{1}$, Jesús Lachica-Valle ${ }^{1}$, Jaime Valle-Leal ${ }^{2}$

\section{Abstract}

BACKGROUND: Relationship of total serum IgE and allergy has been studied to determine if it could be a useful complement allergy diagnosis.

OBJECTIVE: To determine whether serum total IgE is a useful tool in diagnosis of allergy in pediatric population attending outpatient

\footnotetext{
${ }^{1}$ Servicio de Pediatría.

${ }^{2}$ Departamento de Enseñanza e Investigación. Hospital General Regional 1, Instituto Mexicano del Seguro Social, Ciudad Obregón, Sonora, México.

Recibido: 8 de septiembre 2015

Aceptado: 10 de noviembre 2015

Correspondencia

Dr. Jaime Valle Leal

valle_jaime1@hotmail.com

Este artículo debe citarse como Ramírez-Enríquez F, Prado-Rendón J, Lachica-Valle J, Valle-Leal J. Inmunoglobulina E total como marcador de alergia en el noroeste de México. Rev Alerg Méx. 2016 ene-mar;63(1):20-25.
} 
pediatric allergy Regional General Hospital No. 1, Ciudad Obregón, Sonora, Mexico.

MATERIAL AND METHOD: An epidemiological, observational, retrospective, transversal and analytical study of diagnostic test was done including files of children 3-15 years 11 months old, treated in pediatric allergy. For statistical analysis SPSS V-22 was used and through tetrachoric table, sensitivity, specificity of IgE for allergy diagnosis were determined, taking skin tests as a gold standard for diagnosing allergies; $p$ value between the study variables was determined using Student t test.

RESULTS: 248 records were studied; male gender was more frequent (59\%). IgE sensitivity was $85 \%$ and specificity was $20 \%$, cutoff point found was $148 \mathrm{IU} / \mathrm{mL}$, elevated levels of IgE in skin tests to airborne allergens and presence of respiratory symptoms.

CONCLUSIONS: IgE determination is a useful initial screening test in patients with suspected allergy.

KEYWORDS: total serum IgE; atopy; skin tests

\author{
${ }^{1}$ Servicio de Pediatría. \\ ${ }^{2}$ Departamento de Enseñanza e Investi- \\ gación. \\ Hospital General Regional 1, Instituto Mexi- \\ cano del Seguro Social, Ciudad Obregón, \\ Sonora, México.
}

\section{Correspondence}

Dr. Jaime Valle Leal

valle_jaime1@hotmail.com

\section{ANTECEDENTES}

Las enfermedades alérgicas constituyen un grupo de padecimientos frecuentes que incluyen: asma, rinoconjuntivitis alérgica, dermatitis atópica y alergia a los alimentos. ${ }^{1}$ El aumento de estas enfermedades está condicionado por los cambios climáticos, la industrialización y cambios en el entorno del hogar. ${ }^{2}$ La alergia es un proceso mediado por la inmunoglobulina $E$, que es parte fundamental en la fisiopatología del proceso alérgico. ${ }^{3}$ Como prueba diagnóstica, la IgE identifica sujetos atópicos y no atópicos; la sensibilización alérgica se establece con la determinación de lgE específica y pruebas cutáneas; sin embargo, su costo es más elevado y tiene indicaciones precisas. ${ }^{4}$

Los estudios de diversos grupos étnicos han demostrado una asociación entre la prevalencia de diferentes alergias y concentraciones elevadas de IgE sérica total independientes de reactividad específica a las alergias o síntomas de las alergias comunes. ${ }^{5,6}$ La población de estudio está expuesta a gran cantidad de alergenos y las manifestaciones implican visitas frecuentes a urgencias y estancia hospitalaria prolongada.

El objetivo de este trabajo es conocer si la IgE sérica total es una herramienta útil en el diagnóstico de alergia en la población pediátrica del noroeste de México y si permite discernir entre pacientes con enfermedad alérgica y sanos, para establecer un diagnóstico oportuno, tratamiento adecuado y evitar complicaciones.

\section{MATERIAL Y MÉTODO}

Estudio epidemiológico, retrospectivo, transversal, analítico, realizado previa autorización por el Comité de ética e investigación local R-2015-2601-40, bajo el diseño de evaluación de una prueba diagnóstica, con la finalidad de determinar la sensibilidad y especificidad de la inmunoglobulina E (IgE) sérica total para el diagnóstico de alergia en pacientes pediátricos atendidos en el Hospital General Regional 1 del IMSS, en Ciudad Obregón, Sonora, del 1 de mayo de 2014 al 30 de junio de 2015. 
Se incluyeron los expedientes de pacientes que acudieron al servicio de consulta externa de Alergología con sospecha de enfermedad alérgica, género indistinto, entre 3 y 16 años de edad, con resultados de determinación de IgE sérica total y en quienes se realizaron pruebas cutáneas. El muestreo se hizo en dos etapas: por censo (no probabilístico) en una primera etapa, en la que se enlistaron y se tomó registro de todos los pacientes con alergia, y en una segunda etapa, por una elección probabilística al incluir sólo los expedientes con números nones hasta completar 248 expedientes.

Se excluyeron los expedientes con pruebas cutáneas sin reacción a histamina y pruebas cutáneas de control posterior a tratamiento con inmunoterapia. Ningún expediente se eliminó del estudio.

En un formato especial diseñado para este proyecto se registraron las variables: género, edad, resultado de IgE sérica total, representado como positivo mayor de $15 \mathrm{U}$ en el primer año, mayor de 60 de 1 a 5 años, mayor de 90 de 6 a 9 años, mayor de 200 de 10 a 15 años) o negativo (menor de $15 \mathrm{U}$ en el primer año, menor de 60 de $1 \mathrm{a}$ 5 años, menor de 90 de 6 a 9 años, menor de 200 de 10 a 15 años), al tomar como referencia los valores establecidos por el laboratorio del instituto. La IgE se determinó mediante método de inmunofluorescencia indirecta; los resultados de las pruebas cutáneas (patrón de referencia para el diagnóstico de alergia) se consideraron positivos cuando la reacción dérmica fue mayor de $3 \mathrm{~mm}$ o negativos cuando la reacción dérmica fue menor de $3 \mathrm{~mm}$. La técnica se realizó aplicando una gota de extracto alergénico glicerinado, peso volumen (Allergomex) sobre la piel de los antebrazos o de la espalda del paciente. El tipo de alergeno se seleccionó de acuerdo con los prevalentes en cada región geográfica. Los alergenos utilizados se agruparon en cuatro categorías: aeroalergenos, polvo doméstico, alimentos y animales (perro, gato). También se registraron las manifestaciones clínicas iniciales que se catalogaron como respiratorias cuando los pacientes tuvieran rinitis, sinusitis, hiperreactividad bronquial; síntomas cutáneos ante la existencia de pápulas, exantema, eritema y prurito; gastrointestinales, manifestados por diarrea, estreñimiento, borborigmos o flatulencia, y anafilaxia como respuesta potencialmente mortal desencadenada por alergenos.

Los resultados se capturaron en Excel versión 2010 y se analizaron en el programa estadístico SPSS versión 22 para Windows. Con una tabla tetracórica se determinó la sensibilidad y especificidad de la IgE para el diagnóstico de alergias. Para la evaluación de la eficiencia diagnóstica de la IgE sérica total se utilizó el teorema de Bayes (sensibilidad, especificidad); finalmente se correlacionaron las concentraciones de IgE sérica y las manifestaciones clínicas de alergia, así como las concentraciones séricas de IgE y las pruebas cutáneas. El valor de p mediante la prueba t de Student, con IC de 95\%, se consideró con significación cuando fue igual o menor a 0.05.

\section{RESULTADOS}

Se estudiaron 248 expedientes de pacientes atendidos en la consulta externa de Alergología pediátrica con sospecha de enfermedad alérgica, con edades entre 3 y 16 años, en el Hospital General Regional 1 del IMSS en Ciudad Obregón, Sonora, en el periodo comprendido del 1 de mayo de 2014 al 30 de junio de 2015. En el grupo estudiado, 146 pacientes (59\%) pertenecían al género masculino, con relación masculino:femenino de 1.4:1. La edad promedio fue de $8.3 \pm 3.4$ años. La prevalencia de sospecha de enfermedad alérgica fue mayor en la edad escolar y en el género masculino (Cuadro 1).

La sensibilidad de la IgE como prueba diagnóstica fue de $85 \%$ y la especificidad de $20 \%$; 
Ramírez-Enríquez F y col. IgE: marcador de alergia en el noroeste de México

Cuadro 1. Características de la población estudiada. N=248

\begin{tabular}{lc}
\hline Característica & Frecuencia (\%) \\
Edad (años) & \\
3 a 5 & $67(27)$ \\
6 a 11 & $131(53)$ \\
12 a 16 & $50(20)$ \\
Género & \\
Femenino & $102(41)$ \\
Masculino & $146(59)$
\end{tabular}

la sensibilidad más alta encontrada fue para alimentos, seguida por animales, aeroalergenos y polvo doméstico. La mayor especificidad fue para alimentos; se observó una proporción similar para el resto de los alergenos (Cuadro 2).

El valor de la IgE sérica total fue mayor en los pacientes que tuvieron manifestaciones respiratorias y cutáneas; esta diferencia fue estadísticamente significativa, contrario a lo encontrado en las manifestaciones gastrointestinales (Cuadro 3).

Nuestro estudio muestra que las concentraciones séricas de IgE elevadas fueron mayores en pacientes con pruebas cutáneas positivas en general y en pruebas cutáneas positivas para aeroalergenos; estas asociaciones mostraron significación estadística; en sentido opuesto, los alergenos del polvo doméstico, animales y alimentos no mostraron significación estadística. Ningún paciente tuvo reacción de anafilaxia durante la realización de las pruebas (Cuadro 4).

El 58\% ( $n=143)$ de las pruebas cutáneas fueron positivas; la existencia de IgE elevada y pruebas
Cuadro 3. IgE sérica total y tipo de manifestaciones clínicas

\begin{tabular}{lccc}
\hline Síntomas & IgE (UI/mL) & $\mathbf{p}^{*}$ & IC 95\% \\
$\begin{array}{l}\text { Respiratorios } \\
\quad \text { Presentes }\end{array}$ & $1,073 \pm 2,057$ & $0.001^{* *}$ & $(-1,089-20.3)$ \\
$\quad \begin{array}{l}\text { Ausentes } \\
\text { Gastrointestinales } \\
\quad\end{array}$ & $538.7 \pm 668$ & & \\
$\quad \begin{array}{l}\text { Presentes } \\
\quad \text { Ausentes }\end{array}$ & $354 \pm 371.1$ & 0.57 & $(-813-388)$ \\
Cutáneos & $557 \pm 744$ & & \\
$\quad$ Presentes & $1,345 \pm 1,792$ & $0.001^{* *}$ & $(305-1,331)$ \\
$\quad$ Ausentes & $526 \pm 668$ & &
\end{tabular}

*p: t de Student. ${ }^{* *}$ estadísticamente significativos.

Cuadro 4. Concentraciones séricas de IgE y pruebas cutáneas

\begin{tabular}{lccc}
\hline Pruebas cutáneas & IgE $(\mathbf{U I} / \mathbf{m L})$ & $\mathbf{p}$ & IC 95\% \\
Positivas & $687 \pm 880$ & $0.001^{*}$ & $(184-500)$ \\
Negativas & $396 \pm 416$ & & \\
A aeroalergenos & & & \\
$\quad$ Positivas & $759 \pm 896$ & $0.001^{*}$ & $(143-510)$ \\
$\quad$ Negativas & $429 \pm 592$ & & \\
A polvo doméstico & & & \\
$\quad$ Positivas & $693.4 \pm 941$ & $0.015^{*}$ & $(-26-399)$ \\
$\quad$ Negativas & $506.9 \pm 654$ & & \\
A alimentos & & & \\
$\quad$ Positivas & $878 \pm 729$ & 0.42 & $(-54-830)$ \\
$\quad$ Negativas & $540 \pm 736$ & & \\
A animales & & & \\
$\quad$ Positivas & $623 \pm 467$ & 0.45 & $(-222-380)$ \\
$\quad$ Negativas & $544 \pm 763$ & &
\end{tabular}

reactivas para aeroalergenos se encontró en 82 casos, para polvo en 53, animales en 24 y alimentos en 9 .

Respecto de los pacientes que tuvieron concentraciones elevadas de IgE con manifestaciones

Cuadro 2. Sensibilidad y especificidad de lgE sérica total para el diagnóstico de alergias (pruebas cutáneas positivas como patrón de referencia). $\mathrm{N}=248$

\begin{tabular}{lccccc}
\hline Parámetro evaluado & General & Aeroalergenos & Polvo & Animales & Alimentos \\
Sensibilidad & 85 & 88 & 86 & 92 & 100 \\
Especificidad & 20 & 17 & 16 & 16 & 25
\end{tabular}

Las cifras representan porcentajes. 
respiratorias fueron 206 casos, para síntomas cutáneos 6 y gastrointestinales, 3 .

Se encontró una concentración promedio de lgE sérica total de $552 \pm 737.5 \mathrm{UI} / \mathrm{mL}$, con límites de 5 y $5,550 \mathrm{UI} / \mathrm{mL}$. A partir de $400 \mathrm{UI} / \mathrm{mL}$ la sensibilidad de la prueba aumenta, con valores mayores de 1,600 Ul/mL la sensibilidad se acerca al $100 \%$.

Se generó una curva ROC para determinar la sensibilidad y especificidad de la IgE total con la finalidad de encontrar el mejor punto de corte que discrimine el diagnóstico de enfermedad alérgica. La combinación más alta de sensibilidad y especificidad se observó con un corte de 143 UI. En curva ROC área bajo la curva de 0.657, con IC 95\% 0.589-0.726 (Figura 1).

\section{DISCUSIÓN}

Debido a las características geográficas y climatológicas particulares del noroeste de México, éste tiene gran diversidad de alergenos, que

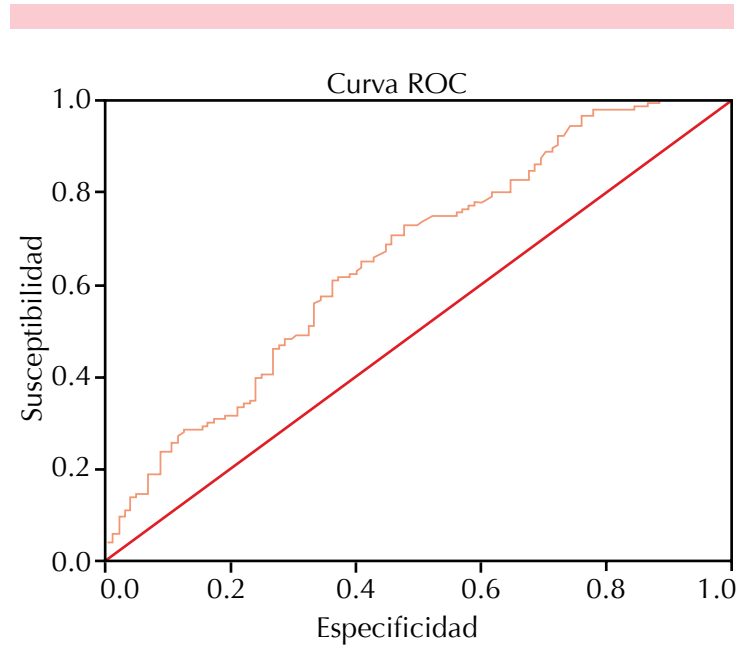

Figura 1. Curva de ROC de la efectividad de IgE sérica total como prueba de tamizaje para pacientes con sospecha de alergias. condicionan sensibilización de la población pediátrica desde etapas muy tempranas de su crecimiento y desarrollo.

Este estudio incluyó síntomas respiratorios, cutáneos y gastrointestinales. Los hallazgos demuestran mayor prevalencia de síntomas respiratorios. La diseminación de los alergenos por vía aérea es más amplia y persistente, lo que explica su mayor prevalencia, ${ }^{3}$ los demás son menos frecuentes, pero de manifestación más insidiosa y su diagnóstico es por exclusión. ${ }^{7,8}$

El valor de referencia establecido para IgE total proporciona sensibilidad de $85 \%$, detecta las posibles sensibilidades hacia alergenos; asimismo, la especificidad diagnóstica calculada en este estudio fue de tan sólo $20 \%$, lo que es significativamente bajo y pareciera indicar que la utilización de la IgE sérica total por sí misma no es específica en aproximadamente $80 \%$ de los casos.

La IgE tiene alta sensibilidad para detectar sensibilización a aeroalergenos en nuestro medio; estos hallazgos apoyan lo encontrado por TlachiCorona y su grupo en 2014 . $^{3}$

El grupo etario con mayor elevación de lgE fue el de escolares, con concentraciones mayores de $400 \mathrm{UI} / \mathrm{mL}$, debido a la exposición y sensibilización a alergenos. Con base en nuestro estudio se define el valor de referencia de las concentraciones de IgE total en los niños del noroeste de México, que es independiente del sexo y de la edad; estos hallazgos apoyan la concentración de IgE para discriminar niños con enfermedad alérgica y sin alergia, con un punto óptimo de corte de $143 \mathrm{UI}$, el doble de lo reportado por Tu en $2013^{8}$ en población asiática (77.7 UI).

Con concentraciones elevadas de IgE la posibilidad de tener pruebas cutáneas positivas se incrementa y, por el contrario, con concentracio- 
nes bajas de inmunoglobulina E la probabilidad de resultados negativos es mayor.

Este estudio proporciona información valiosa acerca de los patrones de sensibilización; sin embargo, se necesitan más investigaciones al respecto para comprender las complejas relaciones entre las exposiciones a alergenos y la aparición de la sensibilización alérgica y la enfermedad.

La IgE en el medio hospitalario continúa siendo un método útil de escrutinio para los pacientes con síntomas respiratorios crónicos, pero no es definitiva porque su especificidad es baja. Sin embargo, como prueba para realizar tamizaje es útil, si se cuenta con ella; el costo es bajo y orienta hacia la toma de decisiones y derivación oportuna.

Algunas limitantes de este estudio fueron el acopio de datos de manera retrospectiva, que limita explorar otros posibles resultados al considerar otros factores, como época del año en que se mida la IgE y se realicen las pruebas cutáneas, así como la clasificación ambigua de los síntomas respiratorios.

\section{CONCLUSIÓN}

La prueba de IgE total en plasma es una herramienta útil de tamizaje inicial en pacientes con sospecha de alergia, cuando sus síntomas principales son respiratorios; la asociación entre pruebas cutáneas positivas y concentraciones elevadas de IgE tuvo significación estadística.

\section{REFERENCIAS}

1. Granada M, Wilk JB, Tuzona M, Strachan DP, et al. A genome wide association study of plasma total IgE concentration in the Framingham heart study. J Allergy Clin Immunol 2012;129:840-845. Disponible en: http://www.ncbi.nlm. nih.gov/pmc/articles/PMC3293994.

2. Sun $B Q$, Chen $D H$, Zheng PY, Huang HM, et al. Allergyrelated evidences in relation to serum IgE: data from the China state key laboratory of respiratory disease, 20082013. Biomed Environ Sci 201;27:495-505. Disponible en: http://www.besjournal.com/Articles/Archive/2014/ No7/201407/P020140729371537264977.pdf

3. Tlachi-Corona L, Caballero-López CG, López-García Al, Papaqui-Tapia $S$, et al. Correlación entre la magnitud de la reactividad cutánea por punción y las concentraciones de IgE sérica específica a pólenes en pacientes con alergia respiratoria. Rev Alergia Mex 2014;61:3-8.

4. Larenas-Linnnemann D, Ortega-Martell J, Rio-Navarro B, Rodríguez N, et al. Guía mexicana de práctica clínica de inmunoterapia 2011. Rev Alergia Mex 2011;58:16-21.

5. Pino-Yanes M, Gignoux CR, Galanter JM, Levin AM, et al. Genome-wide association study and admixture mapping reveal new loci associated with total IgE levels in Latinos. J Allergy Clin Immunol 2014 6:1-9. Disponible en: http://ac.els-cdn.com/S0091674914015759/1-s2.0S0091674914015759-main.pdf?_tid=f5453664-f59e-11e48004-00000aacb362\&acdnat=1431102559_3b727763a82 1fb8f86dd1aeaed4664ee

6. Levin AM, Mathias RA, Huang L, Roth LA, et al. A metaanalysis of genome-wide association studies for serum total IgE in diverse study populations. J Allergy Clin Immunol. [internet]. 2013;131:1176-1184. Disponible en: http:// www.ncbi.nlm.nih.gov/pmc/articles/PMC3596497.

7. Mir E, Panjabi C, Shah A. Impact of allergic rhinitis in school going children. Asia Pac Allergy 2012;2:93-100. Disponible en: http://apallergy.org/Synapse/Data/PDFData/9996APA/ apa-2-93.pdf

8. Tu YL, Chang SW, Tsai HJ, Chen LC, et al. Total serum IgE in a population-based study of Asian children in Taiwan: reference value and significance in the diagnosis of allergy. PLoS ONE. 2013 8(11): [e80996.] Consultado en Agosto de 2015. Disponible en: http://www.plosone.org/ article/fetchObject.action?uri=info:doi/10.1371/journal. pone.0080996\& representation=PDF 